\title{
ENDOCRINE DISRUPTING CHEMICALS AND THEIR DETECTION IN AN IVF LABORATORY
}

\author{
Michal Ješeta ${ }^{1,2}$, Kateřina Franzová ${ }^{1}$, Lenka Mekiňová ${ }^{1}$, Elena Kistanova ${ }^{3}$, Peter Harbulák ${ }^{4}$, Jana
} Žáková ${ }^{,}$Eva Lousová ${ }^{1}$, Pavel Ventruba ${ }^{1}$, Igor Crha ${ }^{1,5}$

\begin{abstract}
The endocrine disruptors are chemicals with the capacity to influence physiological processes in the organism, most often through hormonal control. They are present in the environment and in the products of daily use. They are often found in food, released from plastic bottles for water, present in cosmetics or fertilizers. Latest research suggests that they can be released from plastics used in the IVF laboratories and can be even present in the manipulation and cultivation media used for isolation and fertilization of gametes and subsequent cultivation of embryos. Permanent and long-term utilization of these substances has adverse effects in human reproductive health, mainly by the means of interfering with synthesis and action mechanisms of reproductive hormones. Moreover, some endocrine disruptors show a range of adverse effects directly on the gametes or embryos cultured in the in vitro conditions. The article provides an overview on bisphenols detected in plastics and media commonly used in the IVF laboratory and considers their possible impact on effectiveness of the IVF methods in a human laboratory.
\end{abstract}

Running title: Endocrine disruptors in ART

Keywords: bisphenol, reproduction, endocrine disruptors, oocyte, spermatozoa

\footnotetext{
${ }^{1}$ Department of Obstetrics and Gynecology, University Hospital and Masaryk University, Brno, Czech Republic

${ }^{2}$ Department of Veterinary Sciences, Czech University of Life Sciences in Prague, Prague, Czech Republic

${ }^{3}$ Institute of Biology and Immunology of Reproduction, Bulgarian Academy of Sciences, Sofia, Bulgaria

${ }^{4}$ Gyn-Fiv, Centre for Gynaecology and Assisted Reproduction, Bratislava, Slovak Republic

${ }^{5}$ Department of Health Sciences, Faculty of Medicine, Masaryk University, Brno, Czech Republic

*Correspondence: jeseta.michal@fnbrno.cz

Full list of author information is available at the end of article
} 


\section{Introduction}

There is a large amount of endocrine disruptors (EDs) present in our environment and they are both substances with a short half-life (e.g. bisphenols), and substances persistent in the environment with half-life of several years (perfluorinated bisphenols). The endocrine disruptors are defined as exogenous substances that alter functions of the endocrine system, which leads to adverse health effects. The EDs can interfere with metabolism of various hormones, they can modify their functions or receptors. This wide group of chemical substances includes pesticides, flame retardants, paints, industrial solvents and substances used in production of plastics and other goods of daily use [1]. Due to their widespread use, practically all human population of industrially developed countries is exposed to them. There are several action mechanisms of the endocrine disruptors on reproductive system and gametogenesis. In male, the blood-testis barrier disruption pathway, described for example for BPA or di (2-ethylhexyl) phthalate metabolites, is most important [2]. In such cases, synthesis of proteins necessary for formation of intracellular junctions (occludin, clausin-11) is disrupted, which leads to malfunctions of these junctions and overall instability of the blood-testis barrier [2]. BPA also affects estrogen and androgen receptors in testicles and therefore disrupts steroidogenesis [3]. BPA also shows a positive affinity to the LH receptors and thus disrupts testosterone production in Leydig cells [4]. Patients with the BRCA1 / 2 mutation have even been found to have a higher risk of developing breast cancer due to bisphenols [5]. In women, higher levels of BPA are often associated with lesser numbers and quality of oocytes [6]. In vitro maturation of oocytes in presence of BPA (87 nM) caused disruption of bipolar spindle [7]. Similarly, Ferris et al. [8] reported damaged spindles in bovine COCs exposed to BPA (131 nM). The effects of bisphenols on meiotic maturation of oocytes are often non-linear, when lower concentrations can have worse impact on oocytes [7,9]. In recent years, general use of BPA has been limited. Thanks to regulations, its use in production has been decreased and BPA has not been detected in cultivation media in an IVF laboratory [10]. Comparison of glass and polycarbonate transfer pipettes (releasing BPA) showed no effect on development of embryos related to the presence of BPA [11].

Nevertheless, the limitation of the use of BPA is associated with gradual replacement of BPA with structural analogues of bisphenols that are not monitored as thoroughly as BPA (such as BPS, BPAF, $\mathrm{BPAP}, \mathrm{BPB}, \mathrm{BPF}$ and $\mathrm{BPZ}$ ). The most frequent substitute for BPA is BPS, which has been intensively monitored lately. Some recent studies documented, that BPS disrupts steroid secretion in human granulosa cells and negatively affects quality of ovine oocytes even in nanomolar concentrations [12,13]. It also negatively influences steroidogenesis in ovine granulosa cells similarly to BPA [14]. In bovine oocytes, BPS, just like BPA, disrupted the structure of mitotic spindle during $24 \mathrm{~h}$ of in vitro maturation, even in very low concentrations (10 fM) [9]. The effect was non-linear and did not correlate with increasing concentration of bisphenols.

\section{Presence of EDs disruptors in laboratory equipment}

In the present work, we want to comment on the result of a recent study focused on detection of 10 different bisphenols in IVF laboratories. First, presence of bisphenols in plastic consumables used for IVF procedures was analysed. A total of 17 plastic consumables used commonly in IVF laboratory were included in the study (tubes, tips, cultivation flasks, plates, bottles for media or tubes for cryopreservation). After 24 hours of treatment with methanol, presence of BPA, BPS and 8 more bisphenols was analysed in methanol. BPA, BPS and BPAF were detected in all the 17 samples of plastic consumables. On the contrary, BPAP, BPB, BPC, BPE, BPF, BPP and BPZ were not detected in any of the samples. Regarding the concentrations of the detected bisphenols in comparison with LOQ (limit of quantitation), five consumables contained systematically high concentration of bisphenols (at least 15 times the LOQ). BPAF showed high concentration in the $50 \mathrm{ml}$ centrifugation tube and the cultivation flask. The tips contained BPA and BPS. BPS and BPAF were detected in the bottle for cultivation media. It needs to be emphasized that the bisphenol concentration in methanol only gives information about the plastic composition and gives no significant information about a potential leaching to the IVF media. Therefore, an leaching test was performed for the five consumables with the highest concentrations of the detected bisphenols under conditions similar to those used in common practice. After this treatment, no bisphenols were detected in the leaching water nor in the controls [15].

\section{Presence of EDs in IVF media}

The next focus of the study was on the presence of bisphenols in the IVF cultivation media. A total of 28 media samples from 5 different producers were analysed. They included all kinds of media used in the IVF laboratories (manipulation media, cultivation media, IVM media, holding and washing media and sperm preparation media). BPS was the main bisphenol detected in the evaluated media for cell culture. Six bisphenols (BPA, BPS, BPAF, BPAP, BPE and BPF) (Fig. 1) were found in 18 evaluated media samples, while BPB, BPC, BPP and BPZ were not detected in any of the analysed media samples. BPAP was detected in four samples and its highest concentration was $38 \mathrm{ng} / \mathrm{l}$ (0.13 nM), BPAF was found 
BPA-Bisphenol A

4,4'-Isopropylidenediphenol

BPAF-Bisphenol AF

4-[I, I, I,3,3,3-Hexafluoro-2-(4-hydroxyphenyl)propan-2-yl]phenol

BPAP-Bisphenol AP

4,4'-(I-Phenylethylidene)bisphenol<smiles>CC(C)(c1ccc(O)cc1)c1ccc(O)cc1</smiles><smiles>Oc1ccc(C(c2ccc(O)cc2)(C(F)(F)F)C(F)(F)F)cc1</smiles><smiles>CC(c1ccccc1)(c1ccc(O)cc1)c1ccc(O)cc1</smiles><smiles>O=S(=O)(c1ccc(O)cc1)c1ccc(O)cc1</smiles>

4,4'-Sulfonyldiphenol

BPE-Bisphenol E

I,I-Bis(4-hydroxyphenyl)ethane

BPF-Bisphenol F

Bis(4-hydroxyphenyl)methane
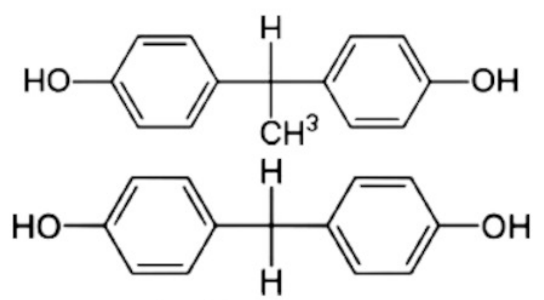

FIGURE 1 Chemical structure of bisphenols detected in IVF media [15]

in 5 samples with the highest concentration $10 \mathrm{ng} / \mathrm{l}$ (0.03 nM), BPF was found in 9 samples in up to 25 $\mathrm{ng} / \mathrm{l}(0.12 \mathrm{nM})$ concentration, BPE was present in 8 media samples in highest concentration $119 \mathrm{ng} / \mathrm{l}$ (0.55 nM), BPA was detected in 9 samples and reached concentration of $155 \mathrm{ng} / \mathrm{l}(0.68 \mathrm{nM})$ and BPS was found in 16 of the 18 samples. BPS was also the bisphenol found in the highest concentrations in all cases: up to $1693 \mathrm{ng} / \mathrm{l}(6.8 \mathrm{nM})$. It exceeded the $1 \mathrm{nM}$ concentration in six samples: $308 \mathrm{ng} / \mathrm{l}$ in Medium 199 with Hepes (1.23 nM), 322 ng/l v BO-IVC (1.28 nM), 338 ng/l v SAGE-1 Step (1.35 nM), 446 ng/l in Flushing Medium (1.78 nM), 750 ng/l in Universal IVF Medium (3,0 nM) and 922 ng/l v Medium 199 (3.69 nM). These concentrations are relatively high, also with regard to the known effect of BPS on oocytes. Of all the bisphenols evaluated in the study, presence of BPS was the most significant in all the analysed media and in high concentrations (1-6.8 $\mathrm{nM}$ ) in 6 of the 18 media samples [15].

These values (mainly the concentrations of BPS) are alarming and it has been documented that concentration of $10 \mathrm{nM}$ during $24 \mathrm{~h}$ maturation of ovine oocytes caused their damage and disruption of subsequent embryonic development [13]. Even a lower concentration (3nM) was sufficient for disruption of meiotic maturation in porcine oocytes [16]. Meiotic maturation is possibly more sensitive to the effects of BPS than embryonic development. Also, during in vitro cultivation, embryo stays in the same environment for 5 days. In addition, deactivation of bisphenols by glucuronidation does not work in the in vitro conditions. That is an important difference from in vivo exposition, where glucuronidation occurs immediately after exposure.

Other foreign chemical substances detected in cultivation media can also have significant adverse effects, while they can also act synergistically. Presence in cultivation media was proven for example for phthalates [17]. The comprehensive work of T. Pollock and his colleagues produced valuable results, describing crosstalk of common EDs. The combined presence of bisphenols is considered to be deleterious [18]. Degradation of bisphenol is inhibited under other EDs exposure and, obviously, the co-exposure achieves various modes for how to 
affect the body [19]. In addition to human and mammalian models, there is an evidence for interaction of xenobiotics and pesticide residua [20], as well as synergistic interactions of organophosphates and pyrethroids [21]. In contrast to synergistic effects leading to an increase of the deleterious impact, competition of some pollutants is known and, surprisingly, a reverse effect of the synergistic activity of pollutants has been described, where one pollutant protects cells against damage caused by another pollutant [22]. The molecular action of interacting pollutants remains to be explained in mammalian models and there is an obvious need for further studies. Also, the results of these studies will influence public health protection.

\section{Conclusions}

Common use of plastic consumables in laboratories is unlikely associated to a high risk of exposure to bisphenols. Nevertheless, surprisingly high concentrations of BPS were detected in cultivation media. An unknown effect of this substance on early embryonic development and potential synergistic effect with other organic substances may pose a future risk for a correct course of in vitro cultivation of human embryos.

People constantly release new chemicals into the environment without a proper evaluation of their effects on human and animal health. Development of chemical production enables rather quick replacement of prohibited substances with new similar analogues suitable for industrial utilization, but with completely unknown effects on health of human and animals. The legislative process is very lengthy and before adverse effects are clearly proven, the harmful substance is spread globally and used commonly in general population including pregnant women and infants.

Current research is insufficiently prepared for solution of this newly developed situation. Most chemicals are not traceable, due to lack of sensitive tests, and their effects cannot be studied using classical methods, since there are no exposed and totally unexposed individuals. Moreover, many EDs potentiate one another's effects and they are often characterized by non-linear effects.

\section{Ethical approval}

The conducted research is not related to either human or animal use.

\section{Acknowledgments}

This independent study was supported by the projects of the Ministry of Health of the Czech Republic No. NV-18-01-00544, NV18-08-00291 and MZ ČR - RVO (FNBr. 65269705).

\section{Corresponding author}

Asss. prof. Ješeta Michal, Ph.D., Department of Obstetrics and Gynecology, University Hospital and Masaryk University, Obilni trh 11, 60200 Brno, Czech Republic, e-mail: jeseta.michal@fnbrno.cz.

\section{Conflict of interest}

The authors declare they have no conflict of interest.

\section{References}

1. Diamanti-Kandarakis E, Bourguignon JP, Giudice LC, Hauser R, Prins GS Soto AM, Zoeller RT, Gore AC. Endocrine-disrupting chemicals: an Endocrine Society scientific statement. Endocr Rev. 2009;30(4):293-342; DOI:10.1210/er.2009-0002.

2. Chiba K, Kondo Y, Yamaguchi K, Miyake H, Fujisawa M. Inhibition of claudin-11 and occludin expression in rat Sertoli cells by mono-(2-ethylhexyl) phthalate through $\mathrm{p} 44 / 42$ mitogen-activated protein kinase pathway. J Androl. 2012;33(3):368-374; DOI:10.2164/jandrol.111.013664.

3. Kitamura S, Suzuki T, Sanoh S, Kohta R, Jinno N, Sugihara K, Yoshihara S, Fujimoto N, Watanabe H, Ohta S. Comparative study of the endocrine-disrupting activity of bisphenol A and 19 related compounds. Toxicol Sci. 2005;84(2):249-259; DOI:10.1093/toxsci/kfi074.

4. Wetherill YB, Akingbemi BT, Kanno J, McLachlan JA, Nadal A, Sonnenschein C, Watson CHS, Zoeller RT, Belcher SM. In vitro molecular mechanisms of bisphenol A action. Reprod Toxicol. 2007;24(2):178-198; DOI:10.1016/j.reprotox.2007.05.010.

5. Ventruba T, Brančíková D, Ventruba P, Minář L, Felsinger M, Vomela J. Breast reconstruction in patients with BRCA mutation and breast cancer - our approach. Cesk Gynekol 2021;86(6): 1-7; DOI:10.48095/ cccg20211.

6. Fujimoto VY, Kim D, vom Saal FS, Lamb JD, Taylor JA, Bloom MS. Serum unconjugated bisphenol A concentrations in women may adversely influence oocyte quality during in vitro fertilization. Fertil Steril. 2011;95(5):1816-1819; DOI:10.1016/j.fertnstert.2010.11.008.

7. Machtinger R, Combelles CM, Missmer SA, Correia KF, Williams P, Hauser R, Racowsky C. Bisphenol A and human oocyte maturation in vitro. Hum Reprod. 2013;28(10):2735-2745; DOI:10.1093/humrep/det312.

8. Ferris J, Favetta LA, King WA. Bisphenol A exposure during oocyte maturation in vitro results in spindle abnormalities and chromosome misalignment in Bos taurus. Cytogenet Genome Res. 2015;145(1):50-58; DOI:10.1159/000381321.

9. Campen KA, Kucharczyk KM, Bogin B, Ehrlich JM, Combelles CMH. Spindle abnormalities and chromosome misalignment in bovine oocytes after exposure to low doses of bisphenol A or bisphenol S. Hum Reprod. 2018;33(5):895-904; DOI:10.1093/humrep/dey050.

10. Gatimel N, Lacroix MZ, Chanthavisouk S, Picard-Hagen N, Gayrard V, Parinaud J, Léandri RD. Bisphenol A in culture media and plastic consumables used for ART. Hum Reprod. 2016;31(7):1436-1444; DOI:10.1093/ humrep/dew116.

11. Moreau J, Gatimel N, Lippi Y, Tavenier G, Fauque P, Guilleman M, Naylies C, Huesca AA, Gayrard V, Parinaud J, Léandri RD. Impact of the polycarbonate strippers used in assisted reproduction techniques on embryonic development. Hum Reprod. 2021;36(2):331-339; DOI:10.1093/ humrep/deaa290.

12. Amar S, Binet A, Téteau O, Desmarchais A, Papillier P, Lacroix MZ, Maillard V, Guérif F, Elis S. Bisphenol S impaired human granulosa cell steroidogenesis in vitro. Int J Mol Sci. 2020;21(5):1821; DOI:10.3390/ ijms21051821.

13. Desmarchais A, Téteau O, Papillier P, Jaubert M, Druart X, Binet A, Maillard $\mathrm{V}$, Elis S. Bisphenol S impaired in vitro ovine early developmental oocyte competence. Int J Mol Sci. 2020;21(4):1238; DOI:10.3390/ijms21041238.

14. Téteau O, Jaubert M, Desmarchais A, Papillier P, Binet A, Maillard V, Elis $\mathrm{S}$. Bisphenol A and S impaired ovine granulosa cell steroidogenesis. Reproduction. 2020;159(5):571-583; DOI:10.1530/REP-19-0575.

15. Togola A, Desmarchais A, Téteau O, Vignault C, Maillard V, Buron C, Bisteau S, Guérif F, Binet A, Elis S. Bisphenol S is present in culture media used for ART and cell culture. Hum Reprod. 2021;36(4):1032-1042; DOI: 10.1093/humrep/deaa365.

16. Žalmanová T, Hošková K, Nevoral J, Prokešová Š, Zámostná K, Kott T, Petr J. Bisphenol S instead of bisphenol A: a story of reproductive disruption by regretable substitution - a review. Czech J Anim Sci. 2016;61(10):433-449; DOI:10.17221/81/2015-CJAS.

17. Takatori S, Akutsu K, Kondo F, Ishii R, Nakazawa H, Makino T. Di(2-ethylhexyl)phthalate and mono(2-ethylhexyl)phthalate in media for in vitro fertilization. Chemosphere. 2012;86(5):454-459; DOI:10.1016/j. chemosphere.2011.09.043

18. Pollock T, Greville LJ, Weaver RE, Radenovic M, deCatanzaro D. Bisphenol S modulates concentrations of bisphenol A and oestradiol in female and male mice. Xenobiotica. 2019;49(5):540-548; DOI:10.1080/00498 254.2018.1480818.

19. Pollock T, Weaver RE, Ghasemi R, deCatanzaro D. A mixture of five endocrine-disrupting chemicals modulates concentrations of bisphenol A 
and estradiol in mice. Chemosphere. 2018;193:321-328; DOI:10.1016/j. chemosphere.2017.11.030.

20. Hawthorne DJ, Dively GP. Killing them with kindness? In-hive medications may inhibit xenobiotic efflux transporters and endanger honey bees. PLoS One. 2011;6(11):e26796; DOI:10.1371/journal. pone.0026796.

21. Johnson RM, Pollock HS, Berenbaum MR. Synergistic interactions between in-hive miticides in Apis mellifera. J Econ Entomol. 2009;102(2):474-479; DOI:10.1603/029.102.0202.

22. Lee GA, Choi KC, Hwang KA. Treatment with phytoestrogens reversed triclosan and bisphenol A-induced anti-apoptosis in breast cancer cells. Biomol Ther (Seoul). 2018;26(5):503-511; DOI:10.4062/ biomolther.2017.160. 